\title{
In-situ Analysis of Passive Films on High Purity Fe-Cr Alloys Using Ellipsometry and Potential-Modulated Reflection Spectroscopy
}

\author{
Nobuyoshi HARA, Shiro MATSUDA ${ }^{1)}$ and Katsuhisa SUGIMOTO
}

Department of Metallurgy, Faculty of Engineering, Tohoku University, Aramaki Aza Aoba, Aoba-ku, Sendai, Miyagi-ken, 980 Japan. 1) Department of Metallurgy, Faculty of Engineering, Tohoku University. Now at Central Research Laboratories, Sumitomo Metal Mining Co., Ltd., Nakakokubun, Ichikawa, Chiba-ken, 272 Japan.

(Received on June 28, 1990; accepted in the final form on September 14, 1990)

\begin{abstract}
Passive films on high purity $\mathrm{Fe}-\mathrm{Cr}$ alloys (13-24 mass\% $\mathrm{Cr}$ ), which were prepared by an Ar plasma melting method using high purity Fe produced by a method combining anion exchange and zone-refining processes and high purity $\mathrm{Cr}$ produced by an iodide process, have been investigated in-situ in $\mathrm{pH} 6.0,1 \mathrm{kmol} \cdot \mathrm{m}^{-3} \mathrm{Na}_{2} \mathrm{SO}_{4}$ using ellipsometry and potentialmodulated reflection spectroscopy. The thickness, $d$, optical constants, $N_{2}$, and cationic mass fractions of $\mathrm{Cr}^{3+}$ ions, $X_{\mathrm{Cr}}$, of the films were determined as a function of potential and $\mathrm{Cr}$ content of the alloy. The same analyses were performed on 400 series ferritic stainless steels $(13-24$ mass $\% \mathrm{Cr}$ ) to elucidate the changes in the film properties with the change in the purity of alloy. It was found that for the passive films on high purity $\mathrm{Fe}-\mathrm{Cr}$ alloys the value of $d$ increased and, at the same time, that of $X_{\mathrm{Cr}}$ decreased with increasing potential. At a given potential, the values of $d$ and $N_{2}$ decreased with increasing $\mathrm{Cr}$ content of the alloy and those of $X_{\mathrm{Cr}}$ increased correspondingly. Similar results were obtained on commercial ferritic stainless steels. The values of $d, N_{2}$ and $X_{\mathrm{Cr}}$ changed in dependence on the purity of alloy. That is, the values of $d$ and $N_{2}$ decreased and those of $X_{\mathrm{Gr}}$ increased with increasing purity. The increase in $X_{\mathrm{Cr}}$ of the films should contribute the increase in the corrosion resistance of the high purity alloys.
\end{abstract}

KEY WORDS: passive film; high purity $\mathrm{Fe}-\mathrm{Cr}$ alloy; chemical composition; film thickness; ellipsometry; modulated reflection spectroscopy.

\section{Introduction}

It has been well known that the removal of harmful impurities from stainless steels brings high corrosion resistances. The authors previously examined the effect of purity of Fe-Cr alloys on the corrosion resistance using three types of $\mathrm{Fe}-\mathrm{Cr}$ alloys, that is, high purity $\mathrm{Fe}-\mathrm{Cr}$ alloys prepared by high purity $\mathrm{Fe}$ and $\mathrm{C}$, vacuum-induction-melted $\mathrm{Fe}-\mathrm{Cr}$ alloys prepared by electrolytic $\mathrm{Fe}$ and $\mathrm{Cr}$, and commercially available ferritic stainless steels. ${ }^{1)}$ This examination demonstrated that the high purity alloys have remarkably low corrosion rates even in the active state in $\mathrm{H}_{2} \mathrm{SO}_{4}$ and $\mathrm{HCl}$ solutions and extremely high corrosion resistance against pitting in chloride solutions. ${ }^{1)}$ The increased corrosion resistance in the active state can be ascribed to increased hydrogen overvoltages, ${ }^{1)}$ while that in chloride solutions should be attributed to improved properties of passive films. In the case of high purity $\mathrm{Fe}$, it has been reported that the formation of thin compact passive films with low defect concentration results in increased resistance to pitting. ${ }^{2)}$ Therefore, it is important to analyze in-situ the nature of passive films on high purity $\mathrm{Fe}-\mathrm{Cr}$ alloys to explain the origin of good corrosion resistance in the passive state.

Among several in-situ techniques for the measurement of surface films in aqueous solutions, ellipsometry and potential-modulated reflection spectro- scopy (PMRS) have been used effectively for the analysis of passive films on highly corrosion resistant metals and alloys.3,4) For example, the ellipsometric determination of thickness and optical constants of the films has been carried out on $\mathrm{Fe}-\mathrm{Cr},{ }^{5)} \mathrm{Fe}-\mathrm{Cr}-\mathrm{Ni}$, ${ }^{6,7)}$ $\mathrm{Fe}-\mathrm{Cr}-\mathrm{Ni}-\mathrm{Mo},{ }^{8-10)} \mathrm{Fe}-\mathrm{Cr}-\mathrm{Ni}-\mathrm{Mn},{ }^{11)}$ and $\mathrm{Fe}-\mathrm{Cr}-\mathrm{Ni}-$ Si alloys. ${ }^{12)}$ The qualitative and quantitative analyses of chemical composition of the films ${ }^{13,14)}$ have been done using PMRS on $\mathrm{Fe}-\mathrm{Cr},{ }^{15-18)} \mathrm{Ni}-\mathrm{Cr}^{18}$ ) and $\mathrm{Ni}-$ $\mathrm{Cr}-\mathrm{Fe}$ alloys. ${ }^{19)}$ The thickness, optical constants and cationic mass fractions of $\mathrm{Cr}^{3+}$ ions of passive films on vacuum-induction-melted $\mathrm{Fe}-\mathrm{Cr}$ alloys have also been determined by these techniques as a function of potential, Cr content of the alloy and solution $\mathrm{pH} .{ }^{5,17}$ )

The aim of the present work is to elucidate changes in the nature and composition of passive films on $\mathrm{Fe}-$ Cr alloy with the change in purity of the alloy. To realize this, the thickness, optical constants and cationic mass fractions of $\mathrm{Cr}^{3+}$ ions of passive films on high purity $\mathrm{Fe}-\mathrm{Gr}$ alloys and commercial ferritic stainless steels have been measured in-situ in a neutral $\mathrm{Na}_{2} \mathrm{SO}_{4}$ solution using ellipsometry and PMRS and results were then compared with those obtained on the vacuum-induction-melted $\mathrm{Fe}-\mathrm{Cr}$ alloys. ${ }^{5,17)}$

\section{Experimental}

\subsection{Specimen}

High purity Fe-Gr alloys with 3 levels of $\mathrm{Cr}$ con- 
tent, i.e., 13, 19 and 24 mass $\%$ Cr, were used as specimens. These alloys were prepared by an Ar plasma melting method using high purity $\mathrm{Fe}$ and $\mathrm{Cr}$ as starting materials. The high purity $\mathrm{Fe}$ was produced by a method combining anion exchange and zone-refining processes. ${ }^{1)}$ The high purity $\mathrm{Cr}$ with nominal purity of 99.99 mass $\%$, which was produced by an iodide process, was purchased from the Materials Research Corporation. The analytical composition of these high purity metals is given in a previous paper, ${ }^{1)}$ and that of the alloys prepared here in Table 1 . Plates $15 \times 15 \times 0.5 \mathrm{~mm}$ were cut from cold-rolled sheets of the alloys and were used without any heattreatment to avoid contamination during the heattreatment. Surfaces of the specimens were polished with $\mathrm{SiC}$ paper up to 1500 grit and then with diamond paste to $1 \mu \mathrm{m}$ finish. After polishing, they were degreased ultrasonically in ethanol and acetone. The surfaces of the specimens were covered with epoxy resin except for the electrode area of $1 \times 10^{-4} \mathrm{~m}^{2}$.

Commercial ferritic stainless steels with 4 levels of Cr content, i.e., 13, 15, 18 and 24 mass \% Gr, were also used as specimens. The analytical composition and heat-treatment conditions of the steels are given in Table 2, Plates $25 \times 15 \times 1 \mathrm{~mm}$ were cut from the cold-rolled sheets of the steels and then subjected to heat-treatments, after which they were polished and degreased in the same manner as high purity $\mathrm{Fe}-\mathrm{Cr}$ alloys.

\subsection{Electrolyte}

A mixture of $1 \mathrm{kmol} \cdot \mathrm{m}^{-3} \quad \mathrm{Na}_{2} \mathrm{SO}_{4}+0.3 \mathrm{kmol} \cdot \mathrm{m}^{-3}$ $\mathrm{H}_{3} \mathrm{BO}_{3}$ and $1 \mathrm{kmol} \cdot \mathrm{m}^{-3} \quad \mathrm{Na}_{2} \mathrm{SO}_{4}+0.075 \mathrm{kmol} \cdot \mathrm{m}^{-3}$ $\mathrm{Na}_{2} \mathrm{~B}_{4} \mathrm{O}_{7}$ (buffered $1 \mathrm{kmol} \cdot \mathrm{m}^{-3} \mathrm{Na}_{2} \mathrm{SO}_{4}$ ) of $\mathrm{pH} 6.0$ was used as an electrolytic solution. All solutions were deaerated by bubbling with purified $\mathrm{N}_{2}$ for more than $43.2 \mathrm{ks}$ before the measurements. The temperature of the solutions was kept at $293 \mathrm{~K}$ throughout the measurements.

\subsection{Electrochemical Polarization}

The passivation of the specimens was accomplished under potentiostatic control. The potential was changed from $-0.60 \mathrm{~V}$ in the noble direction at inter-

Table 1. Chemical composition of high purity Fe-Cr alloys.

\begin{tabular}{|c|c|c|c|c|c|c|c|}
\hline \multirow{2}{*}{ Specimen } & $\mathrm{Cr}$ & G & $\mathrm{P}$ & $\mathrm{S}$ & $\mathrm{Mn}$ & $\mathrm{Cu}$ & W \\
\hline & (mass \%) & \multicolumn{6}{|c|}{ (mass ppm) } \\
\hline H.P. $\mathrm{Fe}-13 \mathrm{Cr}$ & 12.8 & & & & & & \\
\hline H.P. Fe-19Cr & 19.1 & 35 & 5 & 7 & 0.2 & 3 & 2 \\
\hline H.P. $\mathrm{Fe}-24 \mathrm{Cr}$ & 23.6 & & & & & & \\
\hline
\end{tabular}

vals of $100 \mathrm{mV}$. After retention at each potential for $3.6 \mathrm{ks}$, the current and ellipsometric parameters or PMRS spectra were recorded. A saturated calomel electrode (SCE) was used as the reference electrode and the potentials reported here are expressed relative to SCE.

\subsection{Ellipsometry}

A DV-36M Mizojiri-Kogaku ellipsometer, which has a common polarizer-compensator-sample-analyzer configuration, was used. Monochromatic light of wavelength $546.1 \mathrm{~nm}$ was used for the measurements. The angle of incidence of the monochromatic light was $74.42^{\circ}$. The compensator was fixed at an angle of $-45^{\circ}$. Two ellipsometric parameters, the relative phase retardation $\Delta$ and the relative amplitude reduction $\Psi$, were obtained from the angles $P$ and $A$ of the polarizer and the analyzer at the extinction positions.

The thickness and optical constants (complex refractive indices) of passive films were determined using the theoretical $\Delta v s$. $\Psi$ curve which fits the experimental $\Delta v s . \Psi$ curve with minimal error. The theoretical $\Delta$ vs. $\Psi$ curves were calculated using Drude's exact optical equations. The optical constants, $\mathcal{N}_{3}$, for the film-free surfaces of the alloys used in this calculation were obtained from the relationship between $\mathcal{N}_{3}$ and $\mathrm{Cr}$ content for vacuum-inductionmelted $\mathrm{Fe}-\mathrm{Cr}$ alloys (5-60 mass \% $\mathrm{Cr}$ ), which were determined previously in dehydrated methanol immediately after stripping the surface films in a bromine-methanol solution. ${ }^{5}$

\subsection{PMRS}

The PMRS spectra were measured in the photon energy range of 1.6 to $5.5 \mathrm{eV}$. Incident light was polarized parallel to the plane of incidence and the angle of incidence was fixed at $60.0^{\circ}$. In order to modulate the electrode potential, a sinusoidal $a-c$ voltage with a frequency of $65 \mathrm{~Hz}$ was superimposed on the $d-c$ bias potential. The amplitude of the $a-c$ voltage, $\Delta E$, was kept less than $200 \mathrm{mV}_{p-p}$. The measured reflectivity change, $-\Delta R / R$, was normalized to the condition of $\Delta E=100 \mathrm{mV}_{p-p}$ and plotted against the photon energy of incident light. The experimental apparatus used was the same as that described in a previous paper. ${ }^{201}$

\section{Results}

\subsection{Anodic Polarization Curves}

Figs. 1 (a) and 1 (b) show anodic polarization curves in buffered $1 \mathrm{kmol} \cdot \mathrm{m}^{-3} \mathrm{Na}_{2} \mathrm{SO}_{4}$ of $\mathrm{pH} 6.0$ for high purity $\mathrm{Fe}-\mathrm{Cr}$ alloys and commercial ferritic stainless

Table 2. Chemical composition (mass \%) and heat-treatment conditions of commercial ferritic stainless steels.

\begin{tabular}{ccccccccccc}
\hline Specimen & Gr & G & Si & Mn & P & S & Ni & Mo & Cu & Heat-treatment \\
\hline SUS410 (13Cr) & 13.01 & 0.11 & 0.47 & 0.50 & 0.011 & 0.005 & 0.17 & 0.01 & 0.17 & $1073 \mathrm{~K}, 1.8 \mathrm{ks} \rightarrow$ WQ \\
SUS423 (15Cr) & 15.10 & 0.11 & 0.46 & 0.53 & 0.010 & 0.005 & 0.18 & 0.01 & 0.17 & $1073 \mathrm{~K}, 1.8 \mathrm{ks} \rightarrow W Q$ \\
SUS430 (18Cr) & 17.87 & 0.12 & 0.46 & 0.52 & 0.011 & 0.005 & 0.18 & 0.01 & 0.17 & $1123 \mathrm{~K}, 1.8 \mathrm{ks} \rightarrow W Q$ \\
SUS446 (24Gr) & 24.32 & 0.17 & 0.56 & 0.60 & 0.024 & 0.010 & 0.32 & & $1123 \mathrm{~K}, 1.8 \mathrm{ks} \rightarrow W Q$ \\
\hline
\end{tabular}




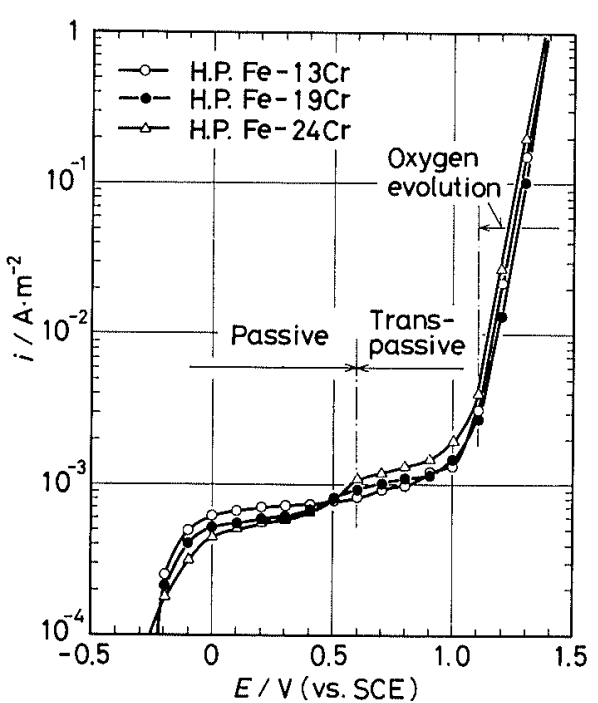

(a)

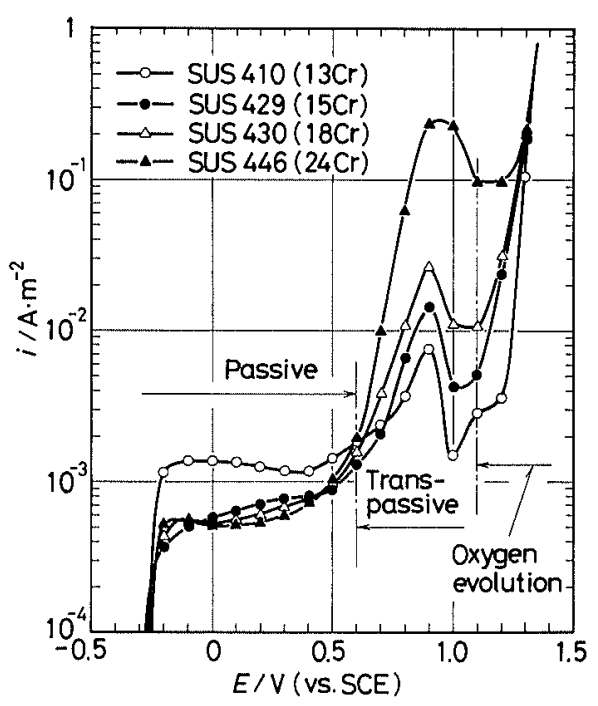

(b)

Fig. 1. Anodic polarization curves for high purity $\mathrm{Fe}-\mathrm{Cr}$ alloys (a) and commercial ferritic stainless steels (b) in $\mathrm{pH} 6,1 \mathrm{kmol} \cdot \mathrm{m}^{-3} \mathrm{Na}_{2} \mathrm{SO}_{4}$.

steels, respectively. These curves consist of 3 regions, that is, the passive $(-0.2$ to $0.6 \mathrm{~V})$, the transpassive $(0.6$ to $1.1 \mathrm{~V})$, and the oxygen evolution (above $1.1 \mathrm{~V}$ ) regions. The current density in the passive region decreases and that in the transpassive region increases with increasing $\mathrm{Cr}$ content. Such a change in current density are more remarkable on the commercial steels. The difference in current between the high purity alloys and commercial steels is small in the passive region, but it becomes large in the transpassive region. The current density of the commercial steels increases sharply when the potential exceeds $0.6 \mathrm{~V}$ and becomes substantially higher than that of the high purity alloys.

\subsection{Thickness and Optical Constants of Passive and Transpassive Films}

\subsubsection{High Purity Fe-Cr Alloys}

Experimental $\Delta$ vs. $\Psi$ curves were measured on a series of high purity $\mathrm{Fe}-\mathrm{Cr}$ alloys after potentiostatic

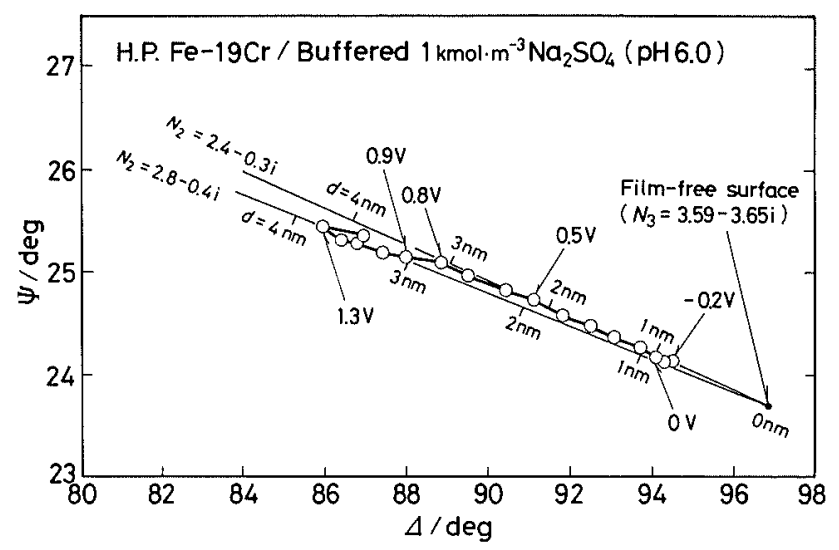

Fig. 2. Experimental $\Delta-\Psi$ locus for the potentiostatic oxidation of high purity $\mathrm{Fe}-19 \mathrm{Cr}$ alloy in $\mathrm{pH} 6,1$ $\mathrm{kmol} \cdot \mathrm{m}^{-3} \quad \mathrm{Na}_{2} \mathrm{SO}_{4}$ and theoretical $\Delta-\Psi$ curves for the growth of films with optical constants $\mathcal{N}_{2}=$ $2.4-0.3 i$ and $2.8-0.4 i$.

oxidation in buffered $1 \mathrm{kmol} \cdot \mathrm{m}^{-3} \mathrm{Na}_{2} \mathrm{SO}_{4}$ of $\mathrm{pH} 6.0$ for $3.6 \mathrm{ks}$. Theoretical $\Delta$ vs. $\Psi$ curves were fitted to the experimental results by a personal computer. Fig. 2 illustrates the case of the high purity $\mathrm{Fe}-19 \mathrm{Cr}$ alloy; the experimental $\Delta v s$. $\Psi$ data are compared with two theoretical $\Delta v s$. $\Psi$ curves which correspond to the growth of films having optical constants of $\mathcal{N}_{2}=2.4-0.3 i$ and $\mathcal{N}_{2}=2.8-0.4 i$. In the calculation of the theoretical curves, 1.356 for the refractive index of $1 \mathrm{kmol} \cdot \mathrm{m}^{-3} \mathrm{Na}_{2} \mathrm{SO}_{4}$ and $3.59-3.65 i$ for the complex refractive index of the matrix of $\mathrm{Fe}-19 \mathrm{Cr}$ alloy ${ }^{5}$ were used.

In the potential range between -0.2 and $0.8 \mathrm{~V}$, the experimental $\Delta v s$. $\Psi$ plot fits well to the theoretical curve calculated for a film with $\mathcal{N}_{2}=2.4-0.3 i$. It can be seen from this theoretical curve that the thickness of the film increases from $0.9 \mathrm{~nm}$ at $-0.2 \mathrm{~V}$ to $3.1 \mathrm{~nm}$ at $0.8 \mathrm{~V}$ with increasing potential. In the potential range between 0.9 and $1.3 \mathrm{~V}$, where the transpassive dissolution and $\mathrm{O}_{2}$ evolution occur, the experimental $\Delta v s . \Psi$ curve coincides with the theoretical curve for a film with $\mathcal{N}_{2}=2.8-0.4 i$ and the thickness of the film increases from $3.0 \mathrm{~nm}$ at $0.9 \mathrm{~V}$ to $3.8 \mathrm{~nm}$ at $1.3 \mathrm{~V}$.

The same analysis was done on the other high purity $\mathrm{Fe}-\mathrm{Cr}$ alloys; the changes in the thickness of passive and transpassive films on the alloys are shown in Fig. 3 as a function of potential. The optical constants, $\mathcal{N}_{2}$, and the increase rates of thickness with an unit rise in potential, $\kappa$, for the films are given in Table 3.

From Fig. 3 it is seen that the thickness of the passive and transpassive films at a given potential decreases as the Cr content of alloy increases. It is shown in Table 3 that the real and imaginary parts of $\mathcal{N}_{2}$ of the films tend to decrease with increasing $\mathrm{Cr}$ content. The real parts of $\mathcal{N}_{2}$ of passive films are smaller than those of transpassive films. The values of $k$ for both passive and transpassive films seems to be approximately independent of $\mathrm{Cr}$ content of the alloy. 


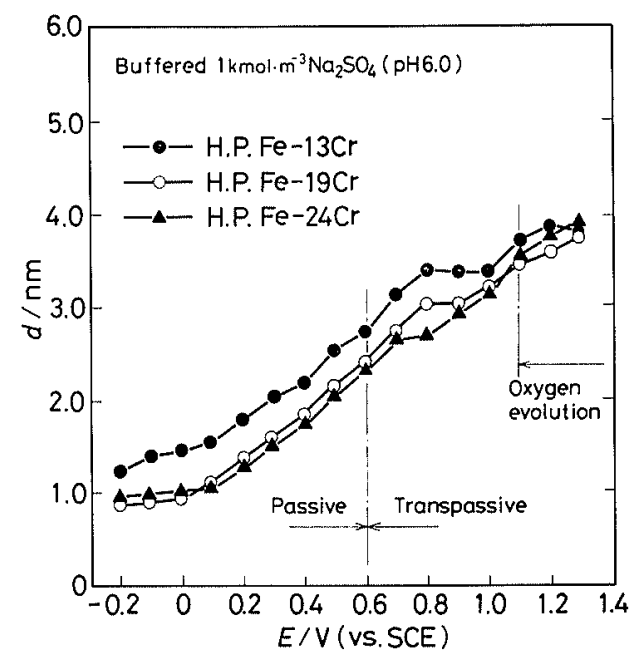

Fig. 3. Thickness, $d$, as a function of potential, $E$, for passive and transpassive films on high purity $\mathrm{Fe}-\mathrm{Cr}$ alloys in $\mathrm{pH} 6,1 \mathrm{kmol} \cdot \mathrm{m}^{-3} \mathrm{Na}_{2} \mathrm{SO}_{4}$.

Table 3. Optical constants, $\mathcal{N}_{2}$, and increase rates of thickness with potential, $\kappa$, for passive and transpassive films formed on high purity $\mathrm{Fe}$ Cr alloys in $\mathrm{pH} 6,1 \mathrm{kmol} \cdot \mathrm{m}^{-3} \mathrm{Na}_{2} \mathrm{SO}_{4}$.

\begin{tabular}{|c|c|c|c|c|}
\hline \multirow[b]{2}{*}{ Specimen } & \multicolumn{2}{|c|}{ Passive film } & \multicolumn{2}{|c|}{ Transpassive film } \\
\hline & $\mathcal{N}_{2}$ & $\mathrm{r}_{\mathrm{V}^{-1}} \cdot$ & $\mathcal{N}_{2}$ & $\kappa / \mathrm{nm}_{\mathrm{V}^{-1}} \cdot$ \\
\hline H.P. Fe-13Cr & $2.5-0.5 i$ & 2.5 & $3.5-0.5 i$ & 2.5 \\
\hline H.P. $\mathrm{Fe}-19 \mathrm{Cr}$ & $2.4-0.3 i$ & 2.5 & $2.8-0.4 i$ & 2.0 \\
\hline H.P. $\mathrm{Fe}-24 \mathrm{Cr}$ & $2.4-0.3 i$ & 2.3 & $2.8-0.4 i$ & 2.7 \\
\hline
\end{tabular}

\subsubsection{Gommercial Ferritic Stainless Steels}

The same measurement and analysis as those described above were done on a series of commercial ferritic stainless steels containing 13-24 mass $\%$ Gr in buffered $1 \mathrm{kmol} \cdot \mathrm{m}^{-3} \mathrm{Na}_{2} \mathrm{SO}_{4}$ of $\mathrm{pH} 6.0$. Fig. 4 shows the results for the SUS429 steel (15Gr steel). In analogy with high purity $\mathrm{Fe}-\mathrm{Cr}$ alloys, the experimental $\Delta v s$. $\Psi$ curve in the potential range between -0.2 and $0.8 \mathrm{~V}$ gives a straight line which coincides with the theoretical curve for the growth of a film with $\mathcal{N}_{2}=2.6-0.5 i$. On the other hand, the experimental $\Delta$ vs. $\Psi$ curve in the transpassive region between 0.8 and $1.1 \mathrm{~V}$ cannot fit to a single theoretical curve corresponding to the growth of a film with a fixed optical constant. That is, the readings of $\Delta$ and $\Psi$ increase abruptly when the potential is changed from 0.8 to $0.9 \mathrm{~V}$, and then decrease as the potential increases from 0.9 to $1.1 \mathrm{~V}$, indicating that both the thickness and optical constant of the film change with potential. Above $1.1 \mathrm{~V}$, the experimental $\Delta v s$. $\Psi$ curve coincides with the theoretical curve for a film with $\mathcal{N}_{2}=3.0-0.6 i$. The same type of changes in $\Delta$ and $\Psi$ with potential was observed on the SUS410 steel (13Gr steel) in the transpassive region.

The results of similar analysis on the other commercial ferritic stainless steels are shown in Fig. 5, where the change in thickness of the passive and transpassive films is given as a function of potential. The optical constants, $\mathcal{N}_{2}$, and the increase rates of thickness with an unit rise in potential, $\kappa$, for the

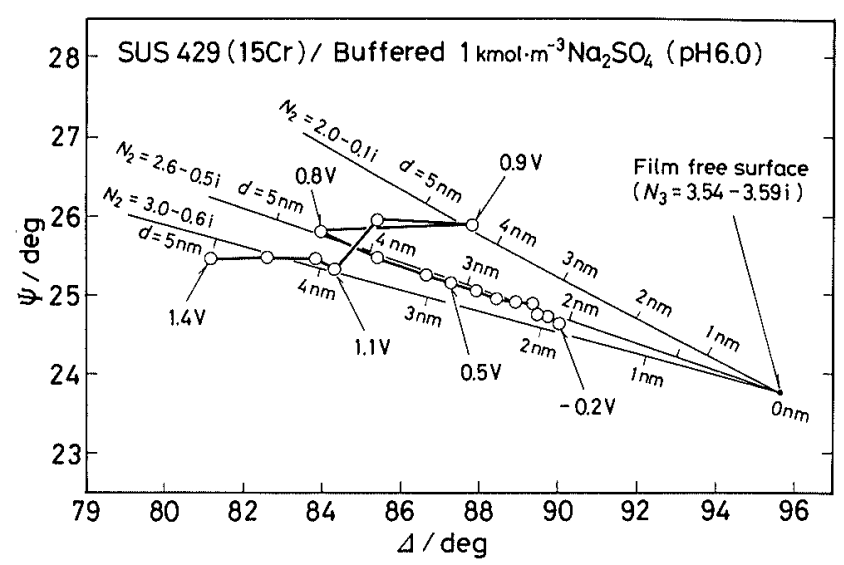

Fig. 4. Experimental $\Delta-\Psi$ locus for the potentiostatic oxidation of SUS429 steel (15Cr steel) in pH 6, 1 $\mathrm{kmol} \cdot \mathrm{m}^{-3} \mathrm{Na}_{2} \mathrm{SO}_{4}$ and theoretical $\Delta-\Psi$ curves for the growth of films with optical constants $\mathcal{N}_{2}=$ $2.6-0.5 i, 3.0-0.6 i$ and $2.0-0.1 i$.

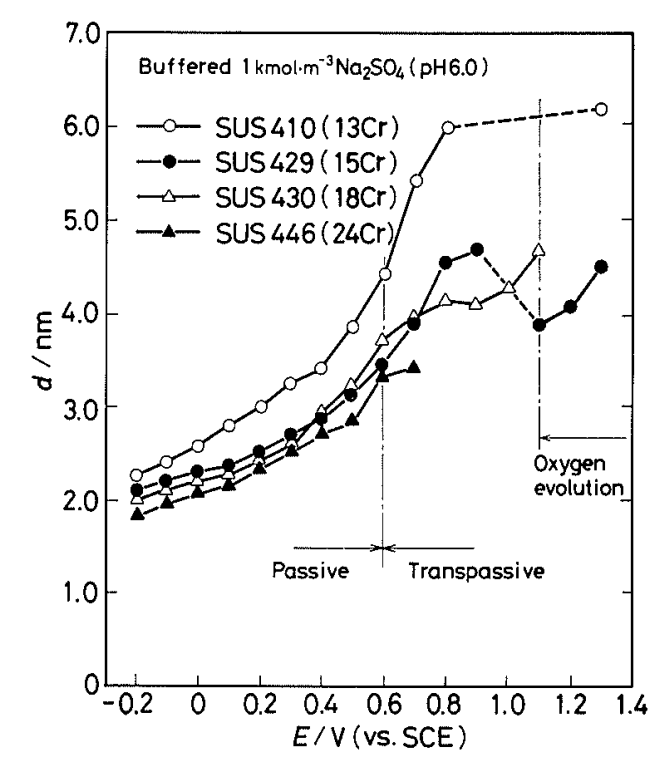

Fig. 5. Thickness, $d$, as a function of potential, $E$, for passive and transpassive films on commercial ferritic stainless steel in $\mathrm{pH} 6,1 \mathrm{kmol} \cdot \mathrm{m}^{-3} \mathrm{Na}_{2} \mathrm{SO}_{4}$.

films are listed in Table 4. In Fig. 5 it can be seen that the thickness of the passive film on each steel increases with increasing potential, and at a given potential the thickness decreases with increasing $\mathrm{Gr}$ content. This consists with the observation on the high purity Fe- $\mathrm{Cr}$ alloys shown in Fig. 3. The tendency that the real part of $\mathcal{N}_{2}$ and the value of $\kappa$ decrease with increasing $\mathrm{Cr}$ content of the steel is seen in Table 4.

\subsection{Chemical Composition of Passive and Transpassive Films}

\subsubsection{High Purity Fe-Cr Alloys}

Fig. 6 illustrates the change in the PMRS spectrum with potential for high purity $\mathrm{Fe}-19 \mathrm{Cr}$ alloy in buffered $1 \mathrm{kmol} \cdot \mathrm{m}^{-3} \mathrm{Na}_{2} \mathrm{SO}_{4}$ of $\mathrm{pH} 6.0$. The spectrum obtained at a potential of $-0.60 \mathrm{~V}$, which is lower than the corrosion potential by ca. $-300 \mathrm{mV}$, shows a peak maximum at $4.8 \mathrm{eV}$ which is close to the characteristic peak position, $5.0 \mathrm{eV}$, for $\mathrm{Cr}(\mathrm{III})$ 
Table 4. Optical constants, $\mathcal{N}_{2}$, and increase rates of thickness with potential, $k$, for passive and transpassive films formed on commercial ferritic stainless steels in $\mathrm{pH} 6,1 \mathrm{kmol}$. $\mathrm{m}^{-3} \mathrm{Na}_{2} \mathrm{SO}_{4}$.

\begin{tabular}{|c|c|c|c|c|}
\hline \multirow[b]{2}{*}{ Specimen } & \multicolumn{2}{|c|}{ Passive film } & \multicolumn{2}{|c|}{ Transpassive film } \\
\hline & $\mathcal{N}_{2}$ & $\stackrel{\kappa / n m}{\mathrm{~V}^{-1}}$ & $\mathcal{N}_{2}$ & $\kappa / \mathrm{nm}_{\mathrm{V}^{-1}}$ \\
\hline SUS410 (13Cr) & $2.6-0.5 i$ & 3.5 & $3.0-0.6 i$ & \\
\hline SUS429 (15Cr) & $2.6-0.5 i$ & 2.7 & $3.0-0.6 i$ & \\
\hline SUS430 (18Cr) & $2.5-0.5 i$ & 2.9 & $3.0-0.5 i$ & 2.2 \\
\hline SUS446 (24Cr) & $2.5-0.5 i$ & 2.1 & & \\
\hline
\end{tabular}

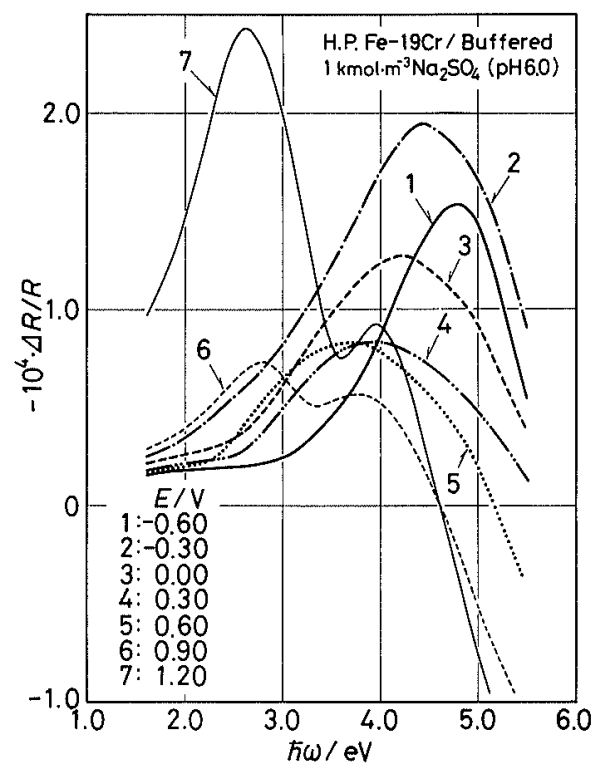

Fig. 6. Change in modulated reflection spectrum with potential, $E$, for high purity $\mathrm{Fe}-19 \mathrm{Cr}$ alloy in $\mathrm{pH}$ $6,1 \mathrm{kmol} \cdot \mathrm{m}^{-3} \mathrm{Na}_{2} \mathrm{SO}_{4}$.

oxides. ${ }^{17,20)}$ The peak maximum, however, shifts to the low photon energy side with increasing potential. At a high potential of $0.60 \mathrm{~V}$ in the passive region the peak maximum appears at $3.6 \mathrm{eV}$ which is close to the characteristic peak position, $3.2 \mathrm{eV}$, for $\mathrm{Fe}$ (III) oxides. ${ }^{17,20)}$ At a potential of $1.2 \mathrm{~V}$ in the $\mathrm{O}_{2}$ evolution region, the peak maximum appears at $2.6 \mathrm{eV}$ which corresponds to the characteristic peak position of $\mathrm{Fe}$ (III) oxides and oxyhydroxides in this potential region. ${ }^{14,17,20)}$ It can be therefore presumed that the films formed at low potentials in the passive region contain a large amount of $\mathrm{Cr}^{3+}$ ions, whereas those formed at high potentials in the passive region and at transpassive and $\mathrm{O}_{2}$ evolution potentials contain a large amount of $\mathrm{Fe}^{3+}$ ions. The same type of changes in spectra with potential was observed on the other high purity $\mathrm{Fe}-\mathrm{Cr}$ alloys.

In order to know the exact composition of passive and transpassive films, the ratio of the signal intensity at $5.0 \mathrm{eV}$ to that at $3.2 \mathrm{eV}, r_{5.0 \mathrm{eV} / 3.2 \mathrm{eV}}$, were evaluated from the spectra measured at each potential, and the cationic mass fractions of $\mathrm{Cr}^{3+}$ ions, $X_{\mathrm{Cr}}$, of the films were then determined using the relations of $r_{5.0 \mathrm{eV} / 3.2 \mathrm{eV}}$ os. $X_{\mathrm{Cr}}$ at corresponding potentials, which were previously derived from the spectra for thin

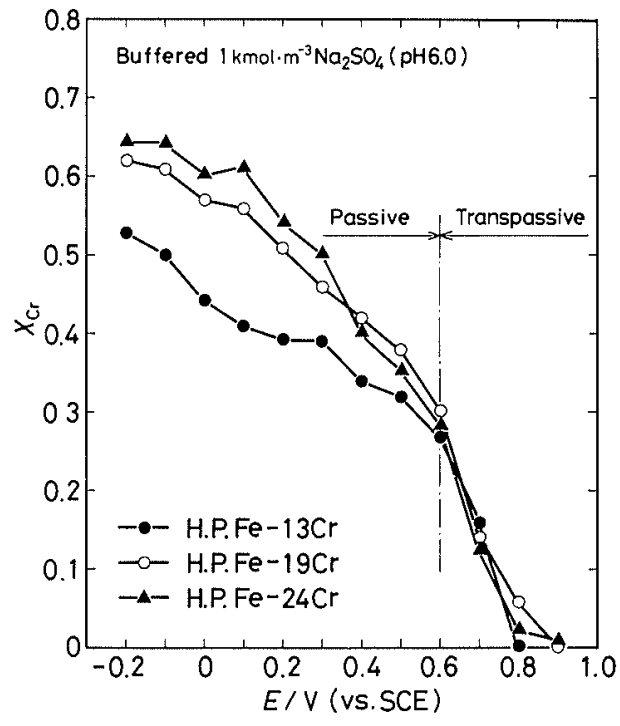

Fig. 7. Cationic mass fraction of $\mathrm{Cr}^{3+}$ ions, $X_{\mathrm{Cr}}$, of passive films on high purity $\mathrm{Fe}-\mathrm{Cr}$ alloys as a function of potential, $E$, in $\mathrm{pH} 6,1 \mathrm{kmol} \cdot \mathrm{m}^{-3} \mathrm{Na}_{2} \mathrm{SO}_{4}$.

composite films of $\mathrm{Fe}_{2} \mathrm{O}_{3}-\mathrm{Cr}_{2} \mathrm{O}_{3}$ prepared on $\mathrm{Pt}$ by MO-GVD technique. ${ }^{17}$

Fig. 7 exhibits thus analyzed changes in $X_{\mathrm{Cr}}$ for the passive and transpassive films formed on high purity $\mathrm{Fe}-\mathrm{Cr}$ alloys in the $\mathrm{pH} 6.0$ solution as a function of potential, $E$. In the passive region between -0.2 and $0.6 \mathrm{~V}$, the value of $X_{\mathrm{Cr}}$ decreases gradually with increasing potential, while at a given potential it increases with increasing $\mathrm{Cr}$ content of the alloy. The values of $X_{\mathrm{Cr}}$ in this region are always higher than the mass fraction of $\mathrm{Cr}, X_{\mathrm{Cr}}$, alloy, of the alloy, indicating the substantial enrichment of $\mathrm{Cr}^{3+}$ ions in the passive film. In the transpassive region above $0.6 \mathrm{~V}$, the value of $X_{\mathrm{Cr}}$ decreases rapidly as the potential increases and becomes less than $X_{\mathrm{Cr} \text {, alloy }}$ at potentials above $0.8 \mathrm{~V}$. This means that $\mathrm{Cr}$ (III) oxides dissolve and thus the depletion of $\mathrm{Cr}^{3+}$ ions occurs at transpassive potentials.

It should be noted that the values of $X_{\mathrm{Cr}}$ given in Fig. 7 is for a very thin region close to the film surface because the spectral information depth of PMRS is as shallow as ca. $0.5 \mathrm{~nm} \cdot{ }^{17,20}$ ) This is due to the fact that PMRS spectra for semiconducting oxide films arise from the field-induced change in the optical constant of the space charge region at the filmelectrolyte interface, whose thickness, $d_{s c}$, is as thin as ca. $0.5 \mathrm{~nm}$ for $\mathrm{Fe}_{2} \mathrm{O}_{3}{ }^{17,21)}$ and $\mathrm{Cr}_{2} \mathrm{O}_{3}$ films. ${ }^{17)}$ Therefore, a steep drop in $X_{\mathrm{Cr}}$ in the transpassive region as shown in Fig. 7 should be attributed to the change in the composition of the outer surface region of films, and there is a possibility that $\mathrm{Cr}^{3+}$ ions may be enriched in the inner region near the film-alloy interface. We previously determined in-depth profiles of $X_{\mathrm{Cr}}$ for the films on vacuum-induction-melted Fe-15Gr alloy using PMRS and ellipsometry combined with the galvanostatic cathodic reduction of the film. ${ }^{17)}$ This results indicate that $\mathrm{Cr}^{3+}$ ions are enriched in the region near the film-alloy interface even in the transpassive films. 


\subsubsection{Commercial Ferritic Stainless Steels}

The changes in PMRS spectra with potential for commercial ferritic stainless steels in buffered $1 \mathrm{kmol}$. $\mathrm{m}^{-3} \mathrm{Na}_{2} \mathrm{SO}_{4}$ of $\mathrm{pH} 6.0$ were similar to those for high purity $\mathrm{Fe}-\mathrm{Cr}$ alloys. The cationic mass fractions of $\mathrm{Cr}^{3+}, X_{\mathrm{Or}}$, of passive and transpassive films on the steels, which were determined in the same manner described above, are given in Fig. 8 as a function of potential. It is seen that the values of $X_{\mathrm{Cr}}$ for passive films on a given steel decrease with increasing potential and those for the films at a given potential increase with increasing $\mathrm{Cr}$ content of the steel, consisting with the observation on the high purity $\mathrm{Fe}-\mathrm{Cr}$ alloys shown in Fig. 7. On the other hand, the changes in $X_{\mathrm{Cr}}$ with potential for transpassive films on the steels differ from those observed on the high purity alloys. In the case of the commercial ferritic stainless steels a steep drop in $X_{\mathrm{Cr}}$ does not occur until the potential exceeds $1.0 \mathrm{~V}$, while such a change in $X_{\mathrm{Cr}}$ occurs at $0.7 \mathrm{~V}$ on the high purity alloys.

\section{Discussion}

In order to examine the effect of the purity of alloy on the nature of passive films, the results obtained here were compared with those previously obtained on vacuum-induction-melted $\mathrm{Fe}-\mathrm{Cr}$ alloys.5,17) From the analytical composition of the alloys, the total content of metallic impurities and that of nonmetallic impurities for the commercial ferritic stainless steels were estimated to be $>10^{4} \mathrm{ppm}$ and $>10^{3} \mathrm{ppm}$, for the vacuum-induction-melted alloys $>500 \mathrm{ppm}$ and $>150 \mathrm{ppm}$, and for the high purity alloys $<10 \mathrm{ppm}$ and $c a .100 \mathrm{ppm}$, respectively. Therefore, the purity of the alloys increases in the following order: the commercial ferritic stainless steel $<$ the vacuum-inductionmelted $\mathrm{Fe}-\mathrm{Cr}$ alloy $<$ the high purity $\mathrm{Fe}-\mathrm{Cr}$ alloy.

\subsection{Effects of the Purity of Alloy on the Thickness, Optical Constant and Chemical Composition of Passive Films}

Fig. 9 illustrates a comparison of the changes in thickness, $d$, and cationic mass fraction of $\mathrm{Cr}^{3+}$ ions, $X_{\mathrm{Cr}}$, of passive films with potential, $E$, (a) and the anodic polarization curves (b) for high purity $\mathrm{Fe}-19 \mathrm{Cr}$ alloy, vacuum-induction-melted $\mathrm{Fe}-19 \mathrm{Cr}$ alloy,17) and commercial SUS430 steel (18Cr steel) in $\mathrm{pH} 6,1 \mathrm{kmol} \cdot \mathrm{m}^{-3} \mathrm{Na}_{2} \mathrm{SO}_{4}$. It can be seen from Fig. 9(a) that, at a given potential in the passive region between -0.2 and $0.6 \mathrm{~V}$, the values of $d$ decrease and those of $X_{\mathrm{Cr}}$ increase with increasing purity, and for each alloy the values of $d$ increase and those of $X_{\mathrm{Cr}}$ decrease with increasing potential. The thickness of the transpassive films formed above $0.6 \mathrm{~V}$ also decreases as the purity of alloy increases. The corresponding values of $X_{\mathrm{Cr}}$, however, decrease with increasing purity in contrast with the case of the passive films. The difference in $d$ and $X_{\mathrm{Cr}}$ between the high purity and vacuum-induction-melted alloys becomes small in the transpassive region.

The optical constants, $\mathcal{N}_{2}$, of passive films on high purity $\mathrm{Fe}-19 \mathrm{Cr}$ alloy, vacuum-induction-melted $\mathrm{Fe}$ $19 \mathrm{Cr}$ alloy and commercial SUS430 steel (18Cr steel)

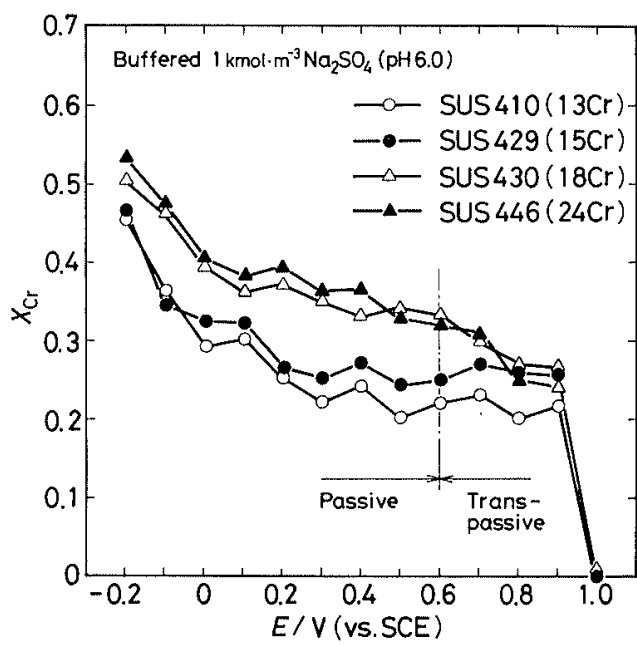

Fig. 8. Cationic mass fraction of $\mathrm{Cr}^{3+}$ ions, $X_{\mathrm{Cr}}$, of passive films on commercial ferritic stainless steels as a function of potential, $E$, in $\mathrm{pH} 6,1 \mathrm{kmol} \cdot \mathrm{m}^{-3} \mathrm{Na}_{2} \mathrm{SO}_{4}$.

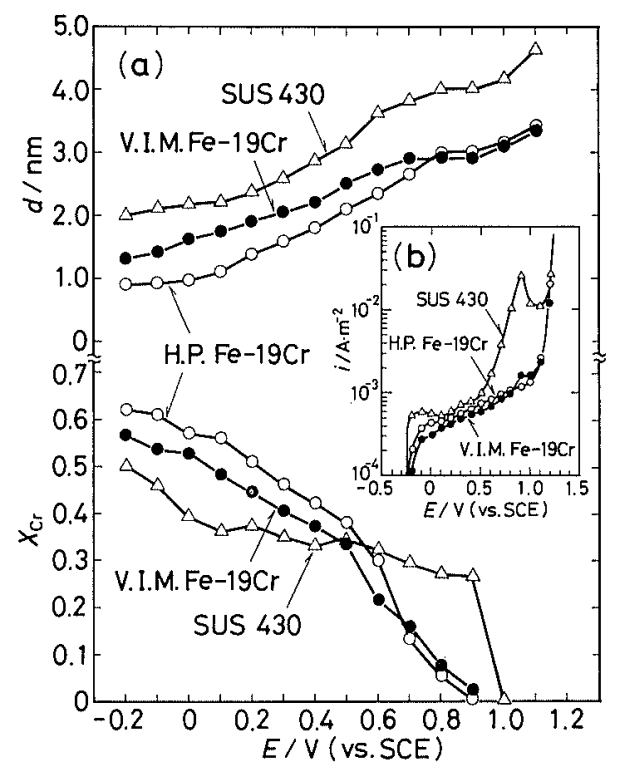

Fig. 9. Thickness, $d$, and cationic mass fraction of $\mathrm{Cr}^{3+}$ ions, $X_{\mathrm{Cr}}$, for passive and transpassive films on high purity $\mathrm{Fe}-19 \mathrm{Cr}$ alloy, vacuum-induction-melted Fe-19Cr alloy and SUS430 steel (18 Cr steel) as a function of potential, $E$, (a) and anodic polarization curves for the alloys and the steel (b) in $\mathrm{pH}$, $1 \mathrm{kmol} \cdot \mathrm{m}^{-3} \mathrm{Na}_{2} \mathrm{SO}_{4}$

are $2.4-0.3 i, 2.5-0.4 i^{7}$ and $2.5-0.5 i$, respectively. The real part of $\mathcal{N}_{2}$ decreases with an increase in the purity of alloy. The decrease in the real part of $\mathcal{N}_{2}$ can be correlated with the increase in $X_{\mathrm{Cr}}$, because the real part of $\mathcal{N}_{2}$ for $\mathrm{Cr}$ oxides is smaller than that for Fe oxides. ${ }^{5}$ )

Fig. 10 exhibits the changes in the thickness, $d$, of the passive films on high purity and vacuum-induction-melted $\mathrm{Fe}-\mathrm{Cr}$ alloys and commercial ferritic stainless steels at $0.50 \mathrm{~V}$ in $\mathrm{pH} 6.0,1 \mathrm{kmol} \cdot \mathrm{m}^{-3}$ $\mathrm{Na}_{2} \mathrm{SO}_{4}$ as a function of $\mathrm{Cr}$ content of the alloys and steels. The corresponding changes in the cationic mass fraction of $\mathrm{Cr}^{3+}, X_{\mathrm{Cr}}$, are shown in Fig. 11 for the films formed at $0.1 \mathrm{~V}$. From these figures, it is clear that at any $\mathrm{Cr}$ content the values of $d$ decrease 


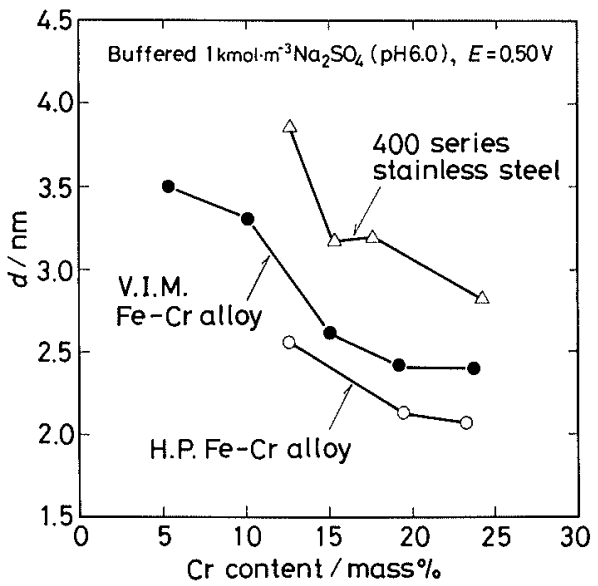

Fig. 10. Thickness, $d$, of passive films on Fe-Cr alloys as a function of $\mathrm{Cr}$ content of the alloys at $0.5 \mathrm{~V}$ in $\mathrm{pH} 6,1 \mathrm{kmol} \cdot \mathrm{m}^{-3} \mathrm{Na}_{2} \mathrm{SO}_{4}$.

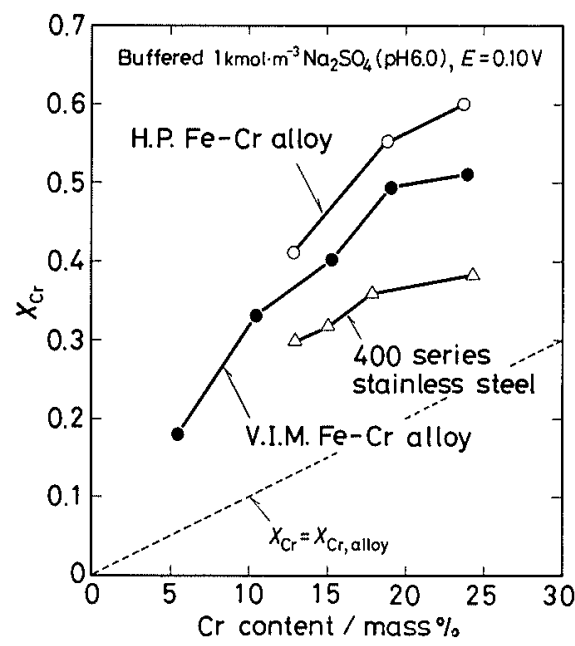

Fig. 11. Cationic mass fraction of $\mathrm{Cr}^{3+}$ ions, $X_{\mathrm{Cr}}$, of passive films on $\mathrm{Fe}-\mathrm{Cr}$ alloys as a function of $\mathrm{Cr}$ content of the alloys at $0.1 \mathrm{~V}$ in $\mathrm{pH} 6,1 \mathrm{kmol} \cdot \mathrm{m}^{-3}$ $\mathrm{Na}_{2} \mathrm{SO}_{4}$.

and those of $X_{\mathrm{Cr}}$ increase with increasing purity, while at a fixed purity the values of $d$ decrease and those of $X_{\mathrm{Cr}}$ increase with increasing $\mathrm{Cr}$ content of the alloy. The same type of changes in $d$ and $X_{\mathrm{Cr}}$ with purity and $\mathrm{Cr}$ content were observed at all potentials in the passivity region.

\subsection{Relationship between the Corrosion Resistance and Properties of Passive Films on $\mathrm{Fe}-\mathrm{Cr}$ Alloy}

From the comparison of passive films on 3 types of $\mathrm{Fe}-\mathrm{Cr}$ alloys with different purities, it is clear that the passive film on $\mathrm{Fe}-\mathrm{Cr}$ alloy becomes thinner and more enriched with $\mathrm{Cr}^{3+}$ ions as the purity of alloy increases. Since the same type of changes in the thickness and composition of the passive film is found as Cr content of the alloy increases, it can be suggested that the increase in purity of $\mathrm{Fe}-\mathrm{Cr}$ alloy brings the same effects on the thickness and composition of the passive film as those produced by the increase in $\mathrm{Cr}$ content of the alloy. In fact, the passive films on high purity $\mathrm{Fe}-13 \mathrm{Cr}$ alloy are comparable to those on commercial $25 \mathrm{Cr}$ steel in terms of the thickness and cationic mass fraction of $\mathrm{Cr}^{3+}$ ions of the films (see Figs. 10 and 11). Such an effect of the increased purity should contribute in part to the increased corrosion resistance of passive films on high purity $\mathrm{Fe}-$ Gr alloys observed in our previous study. ${ }^{1)}$

The removal of metallic and nonmetallic impurities which form carbides and nonmetallic inclusions also improves the spatial uniformity of thickness and composition of the passive films and decreases the defect concentration of the films. This should take part in the increased corrosion resistance of high purity $\mathrm{Fe}-$ Cr alloys.

\subsection{Effects of the Purity of Alloy on the Transpassive Dissolution}

As can be seen in Fig. 9, the transpassive dissolution rate of $\mathrm{Fe}-\mathrm{Cr}$ alloys and the composition of transpassive films on the alloys in a neutral $\mathrm{Na}_{2} \mathrm{SO}_{4}$ solution are remarkably affected by the purity of alloy. Although the increase in current due to the transpassive dissolution is appreciably small on high purity and vacuum-induction-melted $\mathrm{Fe}-\mathrm{Cr}$ alloys, the cationic mass fractions of $\mathrm{Cr}^{3+}$ ions, $X_{\mathrm{Cr}}$, for transpassive films on these alloys decrease rapidly at potentials, $0.6-0.8 \mathrm{~V}$, in the transpassive region and reach almost zero at $0.9 \mathrm{~V}$. It is therefore presumed that in the case of these alloys the transpassive dissolution should be inhibited by the enrichment of Fe(III) oxides in the outer surface region of transpassive films, which is caused by the preferential dissolution of $\operatorname{Cr}$ (III) oxides in the early stage of transpassivity.

In contrast with the high purity and vacuum-induction-melted alloys, commercial ferritic stainless steels show a sharp increase in current density due to the transpassive dissolution, but have appreciably high $X_{\mathrm{Cr}}$ until the potential exceeds $0.9 \mathrm{~V}$. Since the $\mathrm{C}$ content of the commercial steels is about 20 times that of the high purity and vacuum-induction-melted alloys, substantial amounts of $\mathrm{Cr}$ carbides such as $\mathrm{Cr}_{23} \mathrm{C}_{6}$ are precipitated in the commercial steels during the heat-treatment. ${ }^{22,23)}$ The increased current density of commercial ferritic stainless steels in the transpassive region should be due to the preferential dissolution of these Gr carbides. Such preferential dissolution of $\mathrm{Cr}$ carbides may lead to the formation of heterogeneous transpassive films whose thickness and composition vary from site to site. Relatively high values of $X_{\mathrm{Cr}}$ (Figs. 8 and 9) and complex changes in ellipsometric parameters (Fig. 4) observed on the commercial steels in the transpassive region are thought to be concerned with the preferential dissolution of $\mathrm{Gr}$ carbides followed by the formation of spatially heterogeneous transpassive films.

\section{Conclusions}

The thickness, optical constants and the cationic mass fraction of $\mathrm{Ci}^{3+}$ ions of passive films on high purity $\mathrm{Fe}-\mathrm{Cr}$ alloys (13-24 mass \% $\mathrm{Cr}$ ) and commercial ferritic stainless steels (13-24 mass \%) in buffered $1 \mathrm{kmol} \cdot \mathrm{m}^{-3} \mathrm{Na}_{2} \mathrm{SO}_{4}$ of $\mathrm{pH} 6.0$ have been determined in-situ by means of ellipsometry and potential-modu- 
lated reflection spectroscopy, respectively. The results were compared with those obtained previously on vacuum-induction-melted $\mathrm{Fe}-\mathrm{Cr}$ alloys to elucidate effects of the purity of alloy on the film properties.

(1) The thickness of passive films on the high purity alloys increased with increasing potential, and at a given potential it decreases with increasing $\mathrm{Gr}$ content of the alloy. The optical constants tended to decrease as the $\mathrm{Cr}$ content increases. The same type of changes in the thickness and optical constants with potential and $\mathrm{Cr}$ content was observed for passive films on the commercial steels.

(2) The cationic mass fraction of $\mathrm{Cr}^{3+}$ ions, $X_{\mathrm{Cr}}$, for the passive films on the high purity alloys decreased gradually with increasing potential, and the value of $X_{\mathrm{Cr}}$ at a given potential increased with increasing $\mathrm{Cr}$ content of the alloy. Similar changes in $X_{\mathrm{Cr}}$ with potential and $\mathrm{Cr}$ content were observed on the commercial steels in the passive region.

(3) The thickness, optical constant and cationic mass fraction of $\mathrm{Cr}^{3+}$ ions of the passive film on $\mathrm{Fe}$ Cr alloy changed in dependence on purity of the alloy. The thickness and optical constants decreased with increasing purity and the cationic mass fractions of $\mathrm{Cr}^{3+}$ ions increased correspondingly. The increased enrichment of $\mathrm{Cr}^{3+}$ ions in the passive films should contribute to the increased corrosion resistance of the high purity $\mathrm{Fe}-\mathrm{Cr}$ alloy.

\section{REFERENCES}

1) K. Sugimoto, N. Hara, M. Isshiki, T. Ejima and K. Igaki: J. Jpn. Inst. Met., 46 (1982), 703.

2) K. Sugimoto, S. Matsuda, M. Isshiki, T. Ejima and K. Igaki: J.Jpn. Inst. Met., 46 (1982), 155.
3) K. Sugimoto: Tetsu-lo-Hagané, 70 (1984), 637.

4) K. Sugimoto: Bull. Jpn. Inst. Met., 24 (1985), 754.

5) K. Sugimoto and S. Matsuda: Mater. Sci. Eng., 42 (1980), 181.

6) S. Matsuda, K. Sugimoto and Y. Sawada: J. Jpn. Inst. Met., 39 (1975), 848; Trans. Jpn. Inst. Met., 18 (1977), 66.

7) K. Sugimoto and S. Matsuda: Stainless Steels '87, Inst. Met., London, (1988), 201.

8) K. Sugimoto and Y. Sawada: Corros. Sci., 17 (1977), 425.

9) S. Matsuda, K. Hamano, K. Sugimoto and Y. Sawada: J. Jpn. Inst. Met., 42 (1978), 808.

10) S. Matsuda and K. Sugimoto: Corros. Eng. (Jpn.), 29 (1980), 19.

11) S. Matsuda and K. Sugimoto: Corros. Eng. (Jpn.), 32 (1983), 512.

12) S. Matsuda, H. Shimizu and K. Sugimoto: Corros. Eng. (Jpn.), 33 (1984), 71.

13) N. Hara and K. Sugimoto: Corros. Eng. (Jpn.), 36 (1987), 586.

14) N. Hara and K. Sugimoto: Corros. Sci., 31 (1990), 197.

15) N. Hara and K. Sugimoto: Corros. Eng. (Jpn.), 27 (1978), 402.

16) N. Hara and K. Sugimoto: J. Eleclrochem. Soc., 126 (1979), 1328.

17) N. Hara and K. Sugimoto: Passivity of Metals and Semiconductors, ed. by M. Froment, Elsevier Sci. Pub. B.V., Amsterdam, (1983), 211.

18) N. Hara, N. Saito and K. Sugimoto: Corros. Eng. (Jpn.), 35 (1986), 10

19) I. Muto, N. Hara and K. Sugimoto: Corros. Eng. (Jpn.), 37 (1988), 664.

20) N. Hara and K. Sugimoto: J. Jpn. Inst. Met., 43 (1979), 992.

21) U. Stimming and J.W. Schultz: Ber. Bunsenges. Phys. Chem., 80 (1976), 1297.

22) C. B. Post and W.S. Eberly: Trans, Am. Soc. Met., 43 (1951), 243.

23) M. Streicher: Corrosion, 29 (1973), 337. 